\title{
New and Future Drug Development for Gastroesophageal Reflux Disease
}

\author{
Carla Maradey-Romero and Ronnie Fass* \\ The Esophageal and Swallowing Center, Division of Gastroenterology and Hepatology, MetroHealth Medical Center, Case Western Reserve \\ University, Cleveland, Ohio, USA
}

\begin{abstract}
Medical therapy remains the most popular treatment for gastroesophageal reflux disease (GERD). Whilst interest in drug development for GERD has declined over the last few years primarily due to the conversion of most proton pump inhibitor (PPI)'s to generic and over the counter compounds, there are still numerous areas of unmet needs in GERD. Drug development has been focused on potent histamine type 2 receptor antagonist's, extended release PPI's, PPI combination, potassium-competitive acid blockers, transient lower esophageal sphincter relaxation reducers, prokinetics, mucosal protectants and esophageal pain modulators. It is likely that the aforementioned compounds will be niched for specific areas of unmet need in GERD, rather than compete with the presently available anti-reflux therapies.
\end{abstract}

(J Neurogastroenterol Motil 2014;20:6-16)

\section{Key Words}

Erosive esophagitis; Gastroesophageal reflux; Heartburn; Proton pump inhibitors

\section{Introduction}

Gastroesophageal reflux disease (GERD) is a common condition that develops when reflux of stomach contents cause troublesome symptoms and/or complications. ${ }^{1}$ GERD is defined clinically as at least weekly heartburn and/or acid regurgitation. The prevalence of GERD among the adult population in the Western World is reported to be 10-20\%, while in East Asia it ranges from $2.5-7.8 \%{ }^{2,3}$ In the United States (US) GERD is the most common outpatient diagnosis in gastroenterology ${ }^{4}$ and affects $20 \%$ of the adult population weekly and $7 \%$ daily. ${ }^{5,6}$
Most patients with GERD fall into 1 of 3 categories: nonerosive reflux disease (NERD), erosive esophagitis (EE), and Barrett's esophagus (BE). The 2 main phenotypes of GERD, NERD and EE, appear to have different pathophysiological and clinical characteristics. Furthermore, NERD and EE clearly diverge in their response to antireflux treatment. ${ }^{7}$

Currently, the main medical therapeutic modalities for GERD are proton pump inhibitors (PPIs) and histamine type 2 receptor antagonists (H2RAs). The effect of both classes of drugs is mediated through gastric acid suppression, albeit with different potency. Other underlying mechanisms for GERD treatment include neutralizing gastric acidity (antacids), creating

Received: September 29, 2013 Revised: October 25, 2013 Accepted: November 9, 2013

(c) This is an Open Access article distributed under the terms of the Creative Commons Attribution Non-Commercial License (http://creativecommons. org/licenses/by-nc/3.0) which permits unrestricted non-commercial use, distribution, and reproduction in any medium, provided the original work is properly cited.

*Correspondence: Ronnie Fass, MD

Division of Gastroenterology and Hepatology, MetroHealth Medical Center, 2500 MetroHealth Drive, Cleveland, Ohio 44109-1998, USA

Tel: +1-216-778-5736, Fax: +1-216-778-4873, E-mail address: ronnie.fass@gmail.com

Financial support: None.

Conflicts of interest: Ronnie Fass is a reasearcher for Mederi Therapeutics; speaker for Takeda, Astrazeneca and Eisai; and a consultant for Takeda and Given Imaging. 
a foamy raft in the stomach that prevents or replaces gastric acid reflux (alginate-based formulations), and improving esophageal clearance and gastric emptying (prokinetics). The main goals of GERD treatment are to relieve symptoms, heal and maintain remission of EE, prevent complications, and improve health-related quality of life. ${ }^{8}$ Presently, PPIs provide unsurpassed clinical efficacy in GERD patients, primarily due to their profound inhibitory effect on acid secretion. However, even in patients receiving PPI therapy, the resolution of esophageal mucosal inflammation is much more predictable than resolution of symptoms. ${ }^{9}$

The different GERD phenotypes demonstrate varied degrees of response to antireflux treatment. NERD patients, for example,have a significantly lower response rate to PPI therapy as compared with other GERD groups and consequently constitute the majority of patients with refractory heartburn. Failure of PPI therapy is the most common presentation of GERD in gastroenterology practice today. ${ }^{10,11}$

Presently, there are several unmet needs in GERD treatment. Approximately $10-15 \%$ of patients with EE fail to achieve complete healing after 8 weeks of treatment. ${ }^{6}$ Moreover, even when the initial healing PPI dose is continued, 15-23\% of patients with Los Angeles grades A (LA-A) and LA-B EE and $24-41 \%$ of those with LA-C and LA-D EE relapse within 6 months of initiating maintenance treatment. In addition, up to $40 \%$ of NERD patients remain symptomatic while on standard dose (once daily) of PPI therapy. ${ }^{12}$ Treatment of extraesophageal manifestations of GERD has been clinically disappointing. ${ }^{13}$ Most of the randomized controlled trials in patients with pharyngeal, laryngeal, or pulmonary symptoms, which are suspected to be GERD related, demonstrate lack of relief or modest benefit with PPI treatment versus placebo. Other unmet needs in GERD include rapid and more effective control of postprandial heartburn, improved control of volume reflux and acid regurgitation, relief of nighttime heartburn symptoms, acid control in BE patients, and a more flexible schedule of PPI administration. ${ }^{8}$

The goal of the present review is to provide a brief overview of the new and future drug developments for GERD treatment (Table 1).

\section{Histamine Type 2 Receptor Antagonists -}

$\mathrm{H} 2 \mathrm{RAs}$ reduce gastric acid secretion by competitive inhibition of the interaction between histamine and $\mathrm{H} 2$ receptors that are located on the parietal cells. In addition, H2RAs reduce pepsin and gastric acid volume. ${ }^{14}$ Currently, there are 4 Food and Drug Administration (FDA)-approved H2RAs in the US: cimetidine, famatodine, nizatidine and ranitidine.

The different H2RAs are considered equivalent in suppressing gastric acid secretion when administered in equipotent doses. The pharmacokinetic and pharmacodynamic differences among the H2RAs seem to be clinically nonsignificant. ${ }^{15}$ Although $\mathrm{H} 2 \mathrm{RAs}$ are effective in controlling basal acid secretion, they have limited efficacy in suppressing postprandial acid secretion. Presently, H2RAs are used to control symptoms and heal mild to moderate EE (LA-A and LA-B). ${ }^{16}$ In addition, several studies have demonstrated that approximately $30 \%$ of NERD patients report symptom relief after receiving an H2RA twice daily for 4 weeks. ${ }^{17,18} \mathrm{H} 2 \mathrm{RAs}$ are particularly helpful in relieving post-

Table 1. Drugs in Clinical Trial for Gastroesophageal Reflux Disease Treatment

\begin{tabular}{lll}
\hline \multicolumn{1}{c}{ Group } & \multicolumn{1}{c}{ Drug } & \multicolumn{1}{c}{ Clinical trial phase } \\
\hline H2RAs & Lavoltidine & Phase II. Randomized pharmacokinetics/pharmacodynamic study \\
& & Phase I. Nonrandomized pharmacodynamic study \\
PPIs & Ilaprazole & Phase II. Randomized multicenter study \\
& Tenatoprazole & Phase III \\
PPI combination & Vecam & Phase II \\
& OX17 & Phase II \\
& Omeprazole + lansoprazole & Phase I \\
& PPI + alginate & Phase III \\
N-CABs & TAK-438 & Phase II \\
Prokinetics & Macrolides (azithromycin) & Phase II. Placebo-controlled study \\
Pain modulators & TRPV1 (AZD1386) & Phase II. Randomized \\
\end{tabular}

H2RAs, histamine type 2 receptor antagonist; PPIs, proton pump inhibitors; P-CABs, potassium-competitive acid blockers; TLESR, transient lower esophageal sphincter relaxation; TRPV1, transient receptor potential vanilloid 1 . 
prandial heartburn for up to 12 hours. ${ }^{19}$ They are also effective in preventing postprandial heartburn if given 30 minutes before a meal. ${ }^{20}$ In addition, H2RA at bedtime significantly reduce the duration of nocturnal acid breakthrough. ${ }^{21}$

\section{Nizatidine}

Nizatidine is one of the currently available H2RAs. A recent study evaluated the effect of nizatidine on the rate of transient lower esophageal sphincter relaxations (TLESRs) and the level of esophageal acid exposure. Ten healthy subjects were randomized to receive nizatidine $(150 \mathrm{mg})$ twice a day versus placebo 60 minutes before a meal for 7 days. Subsequently, patients underwent esophageal manometry and $\mathrm{pH}$ testing. Nizatidine significantly increased lower esophageal sphincter (LES) basal pressure as compared with placebo. In addition, nizatidine significantly reduced esophageal acid exposure by decreasing the rate of TLESRs and consequently acid exposure as compared with placebo. ${ }^{22}$ The aforementioned effects, in addition to accelerating gastric emptying, are likely due to direct or indirect inhibitory effect of nizatidine on acetylcholinesteresase.

\section{Lafutidine}

This is a novel second generation H2RA. The drug has been primarily used as an antisecretory agent in Japan. In a randomized, double-blind, placebo-controlled study that included 584 subjects with an endoscopic diagnosis of LA-A and LA-B EE, patients received either lafutidine (20 mg once daily), famotidine (40 mg once daily), or placebo for 8 weeks. The authors demonstrated that lafutidine had an endoscopic healing rate of $71 \%$ as compared with $61.4 \%$ and $9.7 \%$, in the famotidine and placebo groups, respectively. ${ }^{23}$ In another study, 23 subjects with heartburn 2 or more times a week, a quality of life and utility evaluation survey technology (QUEST) score of 6 or above, and a negative upper endoscopy, underwent a 24-hour $\mathrm{pH}$ test at baseline and again after 4 weeks of treatment with lafutidine (10 mg twice daily). The authors demonstrated a significant decrease in the percentage of time that intraesophageal $\mathrm{pH}$ was $<4(3.1 \%$ to $1.2 \%)$. In addition, the percentage of time that intragastric $\mathrm{pH}$ $>3$ was also increased significantly (26.6\% to $56.5 \%){ }^{24}$

Another multicenter study compared lafutidine with rabeprazole in treating uninvestigated dyspepsia. Subjects were randomized to lafutidine (10 mg) or rabeprazole (20 mg), both once daily for 4 weeks. Lafutidine and rabeprazole provided a similar rate of symptom relief in patients with heartburn-predominant uninvestigated dyspepsia. The study supports the value of lafutidine as an effective empiric therapy in this subgroup of patients. ${ }^{25}$

\section{Lavoltidine (AH234844)}

Lavoltidine, also known as loxtidine, is a potent noncompetitive H2RA. Because of an increased incidence of carcinoid tumors observed in rats and mice after loxtidine treatment, the drug was suspended in 1988. The carcinogenic effect was probably related to the prolonged achlorhydria that was induced by loxtidine. However, it is unlikely that the drug has similar carcinogenic effect on the human gastric mucosa. ${ }^{26}$ Since lavoltidine has shown rapid onset of action, high potency, and prolonged duration of effect after a single dose, GlaxoSmithKline recently conducted 2 clinical trials with the drug. One study was a phase 2 pharmacokinetic/pharmacodynamic study that was started in 2006. The study compared 4 different AH234844 (lavoltidine) doses (dose range is not available) with esomeprazole (40 mg/day) and ranitidine $(300 \mathrm{mg} / \mathrm{day})$ in healthy male subjects. ${ }^{27}$ Another phase I pharmacodynamic study, which was started in 2007, compared 24-hour intragastric $\mathrm{pH}$ on days 1, 2 and 7 while subjects were on lavoltidine ( $40 \mathrm{mg}$ ) once daily. ${ }^{28}$ Presently, there is no available information about the status of these studies.

One of the main limitations of $\mathrm{H} 2 \mathrm{RAs}$ is tachyphylaxis that develops quickly, usually within 2 weeks of repeated administration. This pharmacological phenomenon results in a decline in acid suppression that limits the regular use of H2RAs in clinical practice. $^{29,30}$ Thus, it is still unknown if the new H2RAs have a similar limitation. Furthermore, it will be important to see if the new H2RAs are more effective in treating GERD patients as compared with the first generation of $\mathrm{H} 2 \mathrm{RAs}$.

\section{Proton Pump Inhibitors}

The introduction of PPIs into the US market in the early late 1980s revolutionized the treatment of acid-peptic disorders. This class of drugs is currently considered the best therapeutic option for GERD. ${ }^{31}$ The high potency of PPIs (omeprazole, lansoprazole, pantoprazole, rabeprazole, esomeprazole and dexlansoprazole $)$ is the result of their ability to inhibit the proton pump $\left(\mathrm{H}^{+}\right.$, $\mathrm{K}^{+}$-ATPase), which is the final common pathway of gastric acid secretion. They suppress nocturnal, daytime and food-stimulated acid secretion. ${ }^{32}$ Currently, PPIs are the most successful antisecretory agents for healing inflammation of the esophageal mucosa and relieving GERD related symptoms because of their profound and sustained acid inhibition. ${ }^{6,14}$ PPIs have made an important therapeutic impact on advanced EE, GERD complica- 
tions and atypical manifestations of GERD. Even in BE, PPIs markedly improved symptoms control, mucosal healing and esophageal acid exposure.

A recent Cochrane review examined 134 therapeutic trials that included 36,978 subjects with EE and concluded that PPIs demonstrated a better healing effect and faster symptom relief than H2RAs. ${ }^{33}$ The study did not find any major difference in efficacy among the currently available PPIs. However, the effect of PPIs on symptoms differs between patients with NERD and those with EE. The symptomatic therapeutic gain of PPIs over placebo in NERD patients is much lower than that observed in patients with EE. ${ }^{34}$ In a systematic review, the therapeutic gain for standard dose PPI in relieving heartburn symptoms compared with placebo ranged from $30 \%$ to $35 \%$ for sufficient heartburn control and from $25 \%$ to $30 \%$ for complete heartburn control. Pooled response rates to PPIs once daily were significantly higher after 4 weeks of treatment for patients with EE compared with NERD patients ( $56 \%$ vs. $37 \%$ ).

Since the introduction of PPIs refractory GERD has become the main presentation of GERD in clinical practice. Specifically, approximately $10-15 \%$ of patients with EE fail to achieve complete healing after 8 weeks of treatment. This subset of patients usually demonstrates moderate to severe disease (LA-C and LA-D) and comprises approximately $25-30 \%$ of all EE patients. Moreover, even when continuing the initial healing dose as maintenance treatment for a period of 6 months, $15-23 \%$ of patients with LA-A or LA-B and $24-41 \%$ of those with LA-C or LA-D relapse while on treatment. In addition, up to $40 \%$ of NERD patients remain symptomatic while on standard dose (once daily) PPI therapy. ${ }^{12}$ Treatment of extraesophageal manifestations of GERD with a PPI has been relatively disappointing, and many trials showed the drug to no better than placebo for improving or relieving symptoms. ${ }^{13}$ Important shortcomings of PPIs include lack of effective control of postprandial and nighttime heartburn as well as esophageal acid exposure in BE patients. In addition, PPIs demonstrate a dependence on food consumption for maximal efficacy.

At present, switching to another PPI or doubling the PPI dose has become the most common therapeutic strategy for GERD patients who symptomatically fail to achieve symptom control on PPI once-daily. ${ }^{10}$ According to a recent Cochrane review, doubling the PPI dose is associated with greater healing of EE, with the number needed to treat of $25 .^{33}$ However, there is no clear dose-response relationship for heartburn resolution in either EE or NERD. ${ }^{34}$ Although doubling the PPI dose has be- come the standard of care, there is no evidence to support further escalation of the PPI dose beyond PPI twice daily for either symptom control or healing EE. When doubling the PPI dose, one dose should be given 30-60 minutes before breakfast and the other 30-60 minutes before dinner. The support for splitting the dose originates primarily from physiological studies demonstrating improved control of intragastric $\mathrm{pH}$ when one dose is taken in the morning and the other in the evening as compared with both doses being taken before breakfast. ${ }^{35}$

Several approaches have been used to improve the acid suppressive effect of PPIs. They include development of enantiomers that undergo slower hepatic metabolism, incorporation of technology that prolongs drug absorption, and production of compounds that maximize PPI absorption and thus bioavailability.

\section{Extended Release Proton Pump Inhibitors}

\section{Dexlansoprazole MR}

Dexlansoprazole MR is a dual delayed-release formulation of dexlansoprazole (R-enantiomer of lansoprazole). The capsule of dexlansoprazole MR contains 2 types of granules that release the drug at different $\mathrm{pH}$ levels (5.5 and 6.8). Consequently, there are dual peaks of drug release in the serum,the first at 1-2 hours after administration and the second at 4-5 hours. ${ }^{36}$ Unlike the delayed-release PPIs, dexlanzoprazole MR can be administered without regard to meals. ${ }^{37}$ Comparative trials demonstrated higher rates of esophageal mucosal healing in subjects with $\mathrm{EE}$ who received dexlansoprazole as compared with those receiving lansoprazole. ${ }^{38}$ Dexlansoprazole MR (30 mg daily for 4 weeks) provides significantly better symptom control as compared with placebo. ${ }^{39}$ Furthermore, the drug is more efficacious than placebo in relieving nocturnal heartburn and reducing GERD-related sleep disturbances when given in a dose of $30 \mathrm{mg}$ daily for a period of 4 weeks. ${ }^{40}$ Dexlansoprazole MR offers greater dosing flexibility, which may improve compliance. While the value of dexlansoprazole MR in patients with PPI failure remains to be elucidated, $88 \%$ of GERD patients requiring twice daily PPI to fully control their symptoms were able to step down to once daily dexlansoprazole MR $30 \mathrm{mg}^{41}$

\section{Tenatoprazole}

Tenatoprazole is a novel compound that, unlike other PPIs, is not a benzimidazole molecule. It is characterized by an imidazopyridine backbone with substantially prolonged plasma half-life. Tenatoprazole (40 mg once daily) demonstrated better 
nighttime acid control than esomeprazole (40 $\mathrm{mg}$ once daily) in healthy subjects. ${ }^{42}$ Another study found that this drug markedly inhibits intragastric acidity unrelated to dosing time or food intake. ${ }^{43}$ S-tenatoprazole-Na, an enantiomer of tenatoprazole, was significantly better in providing gastric acid suppression when compared with esomeprazole (40 mg once daily). Furthermore, it was also demonstrated that higher doses of the drug produced greater acid suppression in a dose-response fashion. ${ }^{44}$

\section{AGN201904-Z (Alevium)}

AGN201904-Z (Alevium) is a prodrug of omeprazole. It is acid-stable and therefore requires no enteric coating. This drug has a long plasma half-life due to slow absorption throughout the small intestine. After absorption, the drug is rapidly hydrolyzed in the systemic circulation to omeprazole. ${ }^{45} \mathrm{~A}$ comparison of Alevium (600 mg once daily) with esomeprazole (40 mg once daily) in 24 healthy subjects resulted in significantly greater and more prolonged acid suppression during both daytime and nighttime. Alevium once daily showed a 1.9 fold increase in serum half-life as compared with esomeprazole. After 5 days of treatment, Alevium demonstrated significantly higher mean 24-hour intragastric $\mathrm{pH}$, nocturnal median $\mathrm{pH}$, and percentage of time intragastric $\mathrm{pH}>4$ was as compared with esomeprazole $(P=0.0001)($ Table 2$){ }^{46}$

\section{Ilaprazole}

Ilaprazole is a benzimidazole compound that is extensively metabolized to the major metabolite ilaprazole sulfone. The drug's antisecretory activity, half-life, and safety profile have all been shown to be superior to omeprazole. ${ }^{47}$ In one randomized study conducted in 235 subjects who had been diagnosed with a duodenal ulcer, ilaprazole at a lower dose (10 mg/day) was better tolerated, safe, and more efficacious than omeprazole. ${ }^{48}$ Another trial investigated ilaprazole at 3 different doses $(5,10$ and $20 \mathrm{mg})$ as compared with omeprazole (20 mg once daily) in 12 healthy subjects. This study demonstrated that $20 \mathrm{mg}$ ilaprazole resulted in a significantly higher mean 24-hour intragastric $\mathrm{pH}$ on day 5 as compared with standard dose of omeprazole $(P<0.05)$. ${ }^{49} \mathrm{~A}$ phase II clinical trial was conducted to evaluate the safety and efficacy of different doses of ilaprazole $(5,20$ and $40 \mathrm{mg})$ as compared with lansoprazole $(30 \mathrm{mg})$ on healing of EE. ${ }^{50}$ Thus far the results of the study remain unavailable.

\section{Esomeprazole stronium delayed-release (Esomezol)}

Esomeprazole stronium delayed-release (Esomezol) is an incrementally modified drug (IMD) manufactured by a pharmaceutical company from South Korea. Strontium salt was used instead of magnesium salt to develop a generic esomeprazole. ${ }^{51}$ No clinical data are currently available in relation to this drug; however, this product has recently received tentative approval from the FDA but has yet to be released into the market. ${ }^{52}$

\section{Proton Pump Inhibitor Combinations}

\section{Proton pump inhibitor-VB101 (Vecam)}

PPI-VB101 (Vecam) is the coadministration of a PPI with a ligand that activates proton pumps in the parietal cells. The rationale behind this combined therapy is to increase the efficacy of

Table 2. Compounds Under Development That Have Been Discontinued

\begin{tabular}{|c|c|c|}
\hline Class & Drug & Reason for discontinuation \\
\hline H2RAs & Loxtidine $^{\mathrm{a}}$ & Neuroendocrine tumors in rats \\
\hline PPIs & AGN201904-Z (Alevium ${ }^{(R)}$ ) & Poor efficacy \\
\hline $\mathrm{P}-\mathrm{CABs}$ & Linaprazan (AZD8065) & Modest or no clinical benefits over PPIs \\
\hline \multirow[t]{6}{*}{ TLESR reducers } & GABA $_{B}$ agonist & \\
\hline & Arbaclofen placarbil & Poor efficacy \\
\hline & Lesogaberan (AZD3335) & Side effects: diarrhea, nausea and increased transaminases \\
\hline & mGluR5 antagonist (ADX10059, AZD2066) & Side effects: increased transaminases and hepatic failure \\
\hline & $\mathrm{CB}$ agonist (rimonabant) & Side effects: depression and suicidal tendencies \\
\hline & $\begin{array}{l}\text { CCK/gastrin receptors antagonist } \\
\text { (spiroglumide, itriglumide and loxiglumide) }\end{array}$ & Poor efficacy \\
\hline Prokinetics & 5-HT 4 receptor agonist (Tegaserod) & Side effects \\
\hline
\end{tabular}

${ }^{a}$ Also see lavoltidine in Table 1 .

H2RAs, histamine type 2 receptor antagonist; PPIs, proton pump inhibitors; P-CABs, potassium-competitive acid blockers; TLESR, transient lower esophageal sphincter relaxation; $\mathrm{GABA}_{\mathrm{B}}, \gamma$-aminobutyric acid class $\mathrm{B}$; mGluR5, metabotropic glutamate receptor 5; $\mathrm{CB}$, cannabinoid; CCK, cholecystokinin; 5-HT 5-hydroxytryptamine 4 receptor. 
the PPI by maximizing activation of proton pumps. In addition, it may allow administration of PPI without regard to food. Vecam is a combination of omeprazole and succinic acid, which has a pentagastrin-like activity that potentiates activation of proton pumps. ${ }^{53}$ In an open-label study, 36 healthy subjects were randomized to receive once daily Vecam (20 or $40 \mathrm{mg}$ ) at bedtime or omeprazole $(20 \mathrm{mg}$ ) before breakfast. The effect of the different therapeutic arms on intragastric acidity was compared over a 24-hour period. Vecam (40 mg) was significantly better at providing greater nighttime intragastric $\mathrm{pH}>4$ as compared with Vecam $(20 \mathrm{mg})$ and omeprazole $(P<0.0001)$. Similarly Vecam $(20 \mathrm{mg})$ showed significantly better control of intragastric $\mathrm{pH}$ as compared with omeprazole $(20 \mathrm{mg})(P=0.0069))^{54}$

\section{OX17}

OX17 is an oral tablet containing a combination of omeprazole and famotidine (doses are unclear). ${ }^{55}$ This combination has shown a $60 \%$ increase in total time intragastric $\mathrm{pH}>4$ as compared with omeprazole alone. A combination of tenatoprazole and H2RA has been recently patented. ${ }^{56}$ However, we are still awaiting studies demonstrating the clinical value of this novel compound as compared with PPI alone.

\section{NMI-826}

NMI-826 is a nitric-oxide (NO)-enhanced PPI. The drug has been shown to be more effective than a PPI alone in healing gastric ulcers. $^{57}$

\section{Secretol}

Secretol is a novel pharmacological compound that combines omeprazole with lansoprazole. Currently, secretol is undergoing a phase II trial that compares its healing rates and symptom control with esomeprazole in subjects with severe EE.

The combined compounds are likely to be niched in certain areas of unmet needs in GERD rather than competing with the currently available PPIs.

\section{Potassium-competitive Acid Blockers}

Potassium-competitive acid blockers (P-CABs) represent a heterogenous group of drugs that shares the same final mechanism of action. This class of drugs inhibits gastric $\mathrm{H}^{+} / \mathrm{K}^{+}$-ATPase in a $\mathrm{K}^{+}$competitive but reversible mechanism. Consequently, P-CABs do not require prior proton pump activation to achieve their anti- secretory effect. P-CABs exhibit an early onset of acid-secretion inhibition due to rapid rise in peak plasma concentration. ${ }^{58}$ Given the pharmacokinetic and pharmacodynamic profile of P-CABs, they are likely to be beneficial as an on-demand therapy for symptomatic GERD.

\section{Linaprazan (AZD8065)}

Linaprazan (AZD8065) demonstrated similar efficacy as esomeprazole in healing and controlling symptoms of GERD patients with EE. ${ }^{59}$ However, the drug did not demonstrate any clinical benefit over esomperazole in symptom control of patients with NERD. ${ }^{60}$

\section{Soraprazan}

Soraprazan showed an immediate inhibition of acid secretion in in vitro models. In animal models, the drug was found to be superior to esomeprazole in onset of action as well as extent and duration of intragastric $\mathrm{pH}>4 .{ }^{61}$ Presently, there are no clinical data available for soraprazan.

\section{Revaprazan}

Revaprazan was demonstrated to be equivalent to PPIs in acid suppression. In a recent study, the authors compared the bioavailability and tolerability of revaprazan alone to revaprezan plus itopride. Revaprazan demonstrated bioequivalence to the combination with itopride without any clinically significant drug-to-drug interaction. ${ }^{62}$

\section{TAK438}

Attempts to develop P-CABs in the last 2 decades have failed to produce even one compound that reached the market. Comparative trials were unable to demonstrate clinical superiority of P-CABs over currently available PPIs. This is primarily due to common utilization of traditional study designs rather than trials that specifically focused on the unique characteristics of $\mathrm{P}-\mathrm{CABs}$. In addition, several P-CABs have been associated with severe adverse effects such as liver toxicity. Thus, despite their promising pharmacokinetics and pharmacodynamics profile, their future in the GERD market remains to be seen.

TAK 438, a new P-CAB, demonstrated greater potency and longer lasting inhibitory effect on gastric acid secretion when compared with lansoprazole. ${ }^{63,64}$ Clinical trials in humans have yet to be published. 


\section{Transient Lower Esophageal Sphincter Relaxation Reducers}

TLESR is the main mechanism of gastroesophageal reflux, both acidic and nonacidic, accounting for all reflux episodes in healthy subjects and the majority (55-80\%) of reflux episodes in GERD patients. ${ }^{65} \mathrm{~A}$ wide range of receptors is involved in triggering TLESR including gamma-aminobutiric acid B $\left(\mathrm{GABA}_{\mathrm{B}}\right)$, metabotropic glutamate receptor 5 (mGlucR5), cannabinoid (CB), cholecystokinin (CCK), 5-hydroxytryptamine 4 $\left(5-\mathrm{HT}_{4}\right)$, muscarinic and opioid. ${ }^{66}$

\section{Cannabinoid Receptor-agonists}

Delta-9-tetrahydrocannabinol, a $\mathrm{CB} 1 / \mathrm{CB} 2$ receptor agonist, inhibits the rate of TLESRs. ${ }^{67}$ A study that evaluated the effect of delta-9-tetrahydrocannabinol on TLESRs in dogs and healthy subjects showed that this compound significantly reduced the number of meal-induced TLESRs. However, the drug also significantly reduced the LES basal pressure. Furthermore, adverse effects such as nausea, vomiting, hypotension and tachycardia led to premature termination of the study. ${ }^{68}$

Rimonabant is a CB1 receptor antagonist. In a placebo-controlled trial that was conducted in healthy subjects, the drug demonstrated increased LES basal pressure and decreased rate of TLESRs and postprandial reflux. The drug was withdrawn from further investigation due to mental side effects such as depression and suicidal tendency. ${ }^{69}$

\section{Cholecystokinin/Gastrin Receptors-antagonist}

Gastrin and $\mathrm{CCK}_{2}$ receptors are identical. Given the physiological importance of gastrin in the stimulation of gastric acid secretion, the development of a selective $\mathrm{CCK}_{2}$ receptor antagonist offers a potential therapeutic choice for acid-related disorders. ${ }^{61,70}$ Only a few CCK-receptor antagonists have been tested in humans, among them spiroglumide, itriglumide and loxiglumide. Loxiglumide has been shown to inhibit the rate of meal-induced TLESR. ${ }^{70-72}$ It is unclear, however, if the effect of loxiglumide is limited to the physiological post-meal increase in TLESRs and reflux episodes, and thus the drug would have no impact on pathological reflux. Itriglumide inhibits gastrin-stimulated acid secretion but might delay mucosal healing; tolerance to the drug may also develop. ${ }^{73}$

Other TLESR reducers have been primarily studied as add-on treatments for patients who failed once-daily PPI.
However, the development of several novel agents targeting this mechanism has met many obstacles, and thus far none has been found to be useful in clinical practice. ${ }^{74}$ These included the $\mathrm{GABA}_{\mathrm{B}}$ agonists arbaclofen placarbil ${ }^{75,76}$ and lesogaberan, ${ }^{77,78}$ as well as the mGlucR5 antagonists ADX10059 ${ }^{32,79}$ and AZD2066. ${ }^{80}$

\section{Prokinetics}

Prokinetic agents have been proposed to improve GERD-related symptoms by different potential mechanisms that include improvement in esophageal peristalsis, acceleration of esophageal acid clearance, increase in LES basal pressure and improved gastric emptying. The clinical benefit of prokinetics as sole treatment for GERD has been modest at best. Moreover, their use has been hampered by many adverse effects.

Mosapride citrate has both $5-\mathrm{HT}_{4}$ receptor agonist and $5-\mathrm{HT}_{3}$ receptor antagonist effects. This drug significantly reduced acid reflux and improved GERD-related symptoms primarily as an add-on therapy. ${ }^{81,82}$

Itopride is a dopamine (D2) receptor antagonist, which also inhibits acetylcholine esterase. This drug has been shown to improve GERD related symptoms and reduce esophageal acid exposure in patients with mild EE. ${ }^{83}$ Itopride inhibits TLESRs without significantly affecting esophageal peristalsis.

Azithromycin is a macrolide with a motilin-agonist properties. The drug also promotes acetylcholine release and stimulates serotonin receptors $\left(5-\mathrm{HT}_{3}\right)$. In a recent study, azithromycin reduced the number of acid reflux events and the size of hiatal hernias as measured by high-resolution manometry. The mean size of the hiatal hernias was larger when reflux episodes were acidic as compared with weakly acidic or nonacidic reflux events. In addition, the acid pocket was more often located below the diaphragm (distal position). ${ }^{84}$ In another study, the effect of azithromycin was evaluated in subjects after lung transplantation. Subjects receiving the drug demonstrated a significantly lower number of total $(P=0.012)$ and number of acid reflux events $(P=0.0037)$ in a 24-hour period as well as bile acids levels in bronchoalveolar lavage fluid $(P=0.0106){ }^{85}$

Prucalopride, a first-in-class dihydrobenzofuran-carboxamide, is a potent selective $5-\mathrm{HT}_{4}$ receptor agonist with enterokinetic properties. The drug is currently used for chronic constipation. Due to its pharmacodynamic profile, the drug may have a role in GERD patients. ${ }^{86}$

Pumosetrag (DDP733) is a partial $5-\mathrm{HT}_{3}$ receptor agonist with GI prokinetic activities. DDP733 increased LES basal 
pressure in experimental animal models. In addition, DDP733 significantly reduced the rate of reflux events and increased the mean amplitude of distal esophageal contractions without changing the LES basal pressure in healthy human subjects. ${ }^{65,87}$

\section{Pain Modulators}

In GERD patients with evidence of esophageal hypersensitivity, such as those with NERD or PPI failure due to nonacidic reflux, pain modulators are likely to play a pivotal therapeutic role. ${ }^{8,12,88}$ Pain modulators, or visceral analgesics, have been shown to significantly improve symptoms in patients with noncardiac chest pain, functional heartburn and refractory GERD. ${ }^{89}$ Non-organ specific pain modulators such as tricyclic antidepressants, trazodone, selective serotonin reuptake inhibitors, and serotonin/norepinephrine reuptake inhibitors are commonly used in clinical practice to treat functional esophageal disorders. ${ }^{90,91}$ It is believed that these agents confer their visceral analgesic effect by acting at the CNS level and/or peripherally at the sensory afferent level.

AZD1386 is a transient receptor potential vanilloid antagonist. In a recent randomized, placebo-controlled study that was conducted in 22 healthy male subjects, the authors evaluated the effect of a single dose AZD1386 (30 and $95 \mathrm{mg}$ ). The authors used a multimodal stimulating probe in the esophagus (distension, heat and electrical stimulation). AZD1386 (30 and $95 \mathrm{mg}$ ) increased esophageal pain thresholds to heat $23 \%$ and $28 \%$, respectively $(P<0.01)$. The drug did not have an effect on perception thresholds for chemical, mechanical or electrical stimuli. ${ }^{88}$ Elevated liver enzymes during drug treatment have been a major concern. ${ }^{92}$ In addition, this drug induced hyperthermia, which could represent a challenge in clinical practice. ${ }^{93}$

\section{Mucosal Protectants}

Rebamipide is an amino acid derivative of 2-(1H)-quinolinone with an anti-inflamatory function and thus may be effective as an esophageal mucosal protectant. A placebo-controlled study in 149 NERD subjects who failed PPI treatment assessed the efficacy of this compound. Unfortunately, the authors were unable to demonstrate a significant effect of rebamipide on subjects' symptoms. ${ }^{94}$ In another study, investigators evaluated the effect of combining a PPI with rebamipide to heal esophageal mucosal ulcers that occurred due to endoscopic submucosal dissection. During the first 2 days after submucosal dissection, all subjects received an intra- venous dose of omeprazole $(20 \mathrm{mg})$ then switched to either rabeprazole $(10 \mathrm{mg})$ once daily alone or to oral rabeprazole plus rebamipide (100 mg) given 3 times daily for 26 days. It was demonstrated that the number of subjects whose ulcer reached the scar stage was significantly greater in the combination group $(68 \%)$ as compared with the PPI group $(35 \%)(P=0.011) .{ }^{95}$

Growth factors, such as epidermal growth factor and macrophage colony-stimulating factors, have a key role in mucosal healing. While early studies in animal models were promising, the value of these growth factors in GERD remains to be studied. $^{96}$

\section{Conclusions}

PPIs have remained the mainstay of treatment in GERD patients. Drug development in GERD has considerably slowed down as most PPIs became generic and were then available over the counter. However, there are still many areas of unmet need in GERDs, so new therapies are needed. Current compounds under development include improved PPIs, TLESR reducers, esophageal-specific pain modulators, and mucosal protectants. Since treatment failure has become the most common presentation of GERD in GI practice, drug development has focused primarily on this specific area of unmet need. However, it would be a grave mistake to neglect other important areas of unmet need in GERD, which provide a unique opportunity for drug development for a large number of patients in dire need of a therapeutic solution. Regardless, it is likely that further innovation in medical therapeutic options for GERD will continue to decline in the next decade.

\section{References}

1. Vakil N, van Zanten SV, Kahrilas P, Dent J, Jones R; Global Consensus Group. The Montreal definition and classification of gastroesophageal reflux disease: a global evidence-based consensus. Am J Gastroenterol 2006;101:1900-1920.

2. Dent J, El-Serag HB, Wallander MA, Johansson S. Epidemiology of gastro-oesophageal reflux disease: a systematic review. Gut 2005; 54:710-717

3. El-Serag HB, Sweet S, Winchester CC, Dent J. Update on the epidemiology of gastro-oesophageal reflux disease: a systematic review. Gut Published Online First: 13 Jul 2013. gutjnl-2012-304269

4. Peery AF, Dellon ES, Lund J, et al. Burden of gastrointestinal disease in the United States: 2012 update. Gastroenterology 2012;143: 1179-1187.

5. Locke GR 3rd, Talley NJ, Fett SL, Zinsmeister AR, Melton LJ 3rd. Prevalence and clinical spectrum of gastroesophageal reflux: a pop- 
ulation-based study in Olmsted County, Minnesota. Gastroenterology 1997;112:1448-1456.

6. Chiba N, De Gara CJ, Wilkinson JM, Hunt RH. Speed of healing and symptom relief in grade II to IV gastroesophageal reflux disease: a meta-analysis. Gastroenterology 1997;112:1798-1810.

7. Hershcovici T, Fass R. Nonerosive reflux disease (NERD)-an update. J Neurogastroenterol Motil 2010;16:8-21.

8. Hershcovici T, Fass R. Gastro-oesophageal reflux disease beyond proton pump inhibitor therapy. Drugs 2011;71:2381-2389.

9. Fass R. Alternative Therapeutic Approaches to Chronic Proton Pump Inhibitor Treatment. Clin Gastroenterol Hepatol 2012;10:338-345.

10. Fass R, Sifrim D. Management of heartburn not responding to proton pump inhibitors. Gut 2009;58:295-309.

11. Fass R. Proton Pump Inhibitor Failure - what are the therapeutic options? Am J Gastroenterol 2009;104(suppl 2):S33-S38.

12. Fass R, Shapiro M, Dekel R, Sewell J. Systematic Review: proton-pump inhibitor failure in gastro-oesophageal reflux disease-where next? Aliment Pharmacol Ther 2005;22:79-94.

13. Moore JM, Vaezi MF. Extraesophageal manifestations of gastroesophageal reflux disease: real or imagined? Curr Opin Gastroenterol 2010;26:389-394.

14. Fass R, Hixson LJ, Ciccolo ML, Gordon P, Hunter G, Rappaport W. Contemporary medical therapy for gastroesophageal reflux disease. Am Fam Physician 1997;5 5:205-212, 217-218.

15. Wolfe MM, Sachs G. Acid suppression: optimizing therapy for gastroduodenal ulcer healing, gastroesophageal reflux disease, and stress-related erosive syndrome. Gastroenterology 2000;118(2 suppl 1):S9-S31.

16. Wang WH, Huang JQ, Zheng GF, et al. Head-to-head comparison of H2-receptor antagonists and proton pump inhibitors in the treatment of erosive esophagitis: a meta-analysis. World J Gastroenterol 2005;11:4067-4077.

17. Venables TL, Newland RD, Patel AC, Hole J, Wilcock C, Turbitt ML. Omeprazole 10 milligrams once daily, omeprazole 20 milligrams once daily, or ranitidine 150 milligrams twice daily, evaluated as inicitial therapy for the relief of symptoms of gastro-oesophageal reflux disease in general practice. Scand J Gastroenterol 1997;32:965-973.

18. Fujiwara Y, Higuchi K, Nebiki H, et al. Famotidine vs. omeprazole: a prospective randomized multicentre trial to determine efficacy in non-erosive gastro-esophageal reflux disease. Aliment Pharmacol Ther 2005;21(suppl 2):10-18.

19. Pappa KA, Gooch WM, Buaron K, et al. Low-dose ranitidine for the relief of heartburn. Aliment Pharmacol Ther 1999;13:459-465.

20. Pappa KA, Williams BO, Payne JE, Buaron KS, Mussari KL, Ciociola AA. A double-blind, placebo-controlled study of the efficacy and safety of non-prescription ranitidine $75 \mathrm{mg}$ in the prevention of meal-induced heartburn. Aliment Pharmacol Ther 1999;13:467-473.

21. Peghini PL, Katz PO, Castell DO. Ranitidine controls nocturnal gastric acid breakthrough on omeprazole: a controlled study in normal subjects. Gastroenterology 1998;115:1335-1339.

22. Iwakiri K, Kawami N, Sano H, et al. The effects of nizatidine on transient lower esophageal sphincter relaxations (TLESRs) and acid reflux in healthy subjects. J Smooth Muscle Res 2011;47:157-166.

23. Ohara S, Haruma K, Kinoshita Y, Kusano M. A double-blind, controlled study comparing lafutidine with placebo and famotidine in Japanese patients with mild reflux esophagitis. J Gastroenterol
2010;45:1219-1227.

24. Inamori $\mathrm{M}$, Iida $\mathrm{H}$, Hosono $\mathrm{K}$, et al. The histamine $\mathrm{H} 2$ receptor antagonist lafutidine in Japanese patients with non-erosive reflux disease. Hepatogastroenterology 2010;57:1430-1434.

25. Dewan B, Philipose N. Lafutidine $10 \mathrm{mg}$ versus rabeprazole $20 \mathrm{mg}$ in the treatment of patients with heartburn-dominant uninvestigated dyspepsia: a randomized, multicentric trial. Gastroenterol Res Pract 2011;2011:640685.

26. Gatehouse D, Wedd DJ, Paes D, et al. Investigations into the genotoxic potential of loxtidine, a long-acting $\mathrm{H} 2$ receptor antagonist. Mutagenesis 1998;3:57-58.

27. NCT00405119. A study to investigate the effectiveness of AH234844 (Lavoltidine) compared with nexium and ranitidine. Available from URL: http://clinicaltrials.gov/show/NCT00405119 (accessed November 2013).

28. NCT00551473. Open-label comparison of $24 \mathrm{hr}$ gastric $\mathrm{pH}$ on Days 1, 2, 7 with once-daily administration of Lavoltidine $40 \mathrm{mg}$. Available from URL: http://clinicaltrials.gov/show/NCT00551473 (accessed November 2013).

29. Fackler WK, Ours TM, Vaezi MF, Richter JE. Long-term effect of H2RA therapy on nocturnal gastric acid breakthrough. Gastroenterology 2002;122:625-632.

30. Scarpignato C. New drugs to suppress acid secretion: current and future developments. Drug Discov Today Ther Strateg 2007;4:155-163.

31. Horn J. The proton-pump inhibitors: similarities and differences. Clin Ther 2000;22:266-280.

32. Howden CW. Appropriate acid suppression in the treatment of acid-related conditions. Pharmacol Ther 1994;63:123-134.

33. Khan M, Santana J, Donnellan C, Preston C, Moayyedi P. Medical treatments in the short term management of reflux oesophagitis. Cochrane Database Syst Rev 2007;(2):CD003244.

34. Dean BB, Gano AD Jr, Knight K, Ofman JJ, Fass R. Effectiveness of proton pump inhibitors in nonerosive reflux disease. Clin Gastroenterol Hepatol 2004;2:656-664.

35. Hatlebakk JG, Katz PO, Kuo B, Castell DO. Nocturnal gastric acidity and acid breakthrough on different regimens of omeprazole $40 \mathrm{mg}$ daily. Aliment Pharmacol Ther 1998;12:1235-1240.

36. Hershcovici T, Jha LK, Fass R. Dexlansoprazole MR: a review. Ann Med 2011;43:366-374.

37. Lee RD, Vakily M, Mulford D, Wu J, Atkinson SN. Clinical trial: the effect and timing of food on the pharmacokinetics and pharmacodynamics of dexlansoprazole MR, a novel Dual Delayed Release formulation of a proton pump inhibitor - evidence for dosing flexibility. Aliment Pharmacol Ther 2009;29:824-833.

38. Sharma P, Shaheen NJ, Perez MC, et al. Clinical trials: healing of erosive oesophagitis with dexlansoprazole MR, a proton pump inhibitor with a novel dual delayed-release formulation - results from two randomized controlled studies. Aliment Pharmacol Ther 2009; 29:731-741.

39. Fass R, Chey WD, Zakko SF, et al. Clinical trial: The effects of the proton pump inhibitor dexlansoprazole MR on daytime and nighttime heartburn in patients with non-erosive reflux disease. Aliment Pharmacol Ther 2009;29:1261-1272.

40. Fass R, Johnson DA, Orr WC, et al. The effect of dexlansoprazole MR on nocturnal heartburn and GERD-related sleep disturbances in patients with symptomatic GERD. Am J Gastroenterol 2011; 
106:421-431.

41. Fass R, Inadomi J, Han C, Mody R, O’Neil J, Perez MC. Maintenance of heartburn relief after step-down from twice-daily proton pump inhibitor to once-daily dexlansoprazole modified release. Clin Gastroenterol Hepatol 2012;10:247-253.

42. Galmiche JP, Bruley Des Varannes S, Ducrotté P, et al. Tenatoprazole, a novel proton pump inhibitor with a prolonged plasma half-life: effects on intragastric $\mathrm{pH}$ and comparison with esomeprazole in healthy subjects. Aliment Pharmacol Ther 2004;19:655-662.

43. Thomson AB, Cohen P, Ficheux H, et al. Comparison of the effects of fasting morning, fasting evening and fed bedtime administration of tenatoprazole on intragastric $\mathrm{pH}$ in healthy volunteers: a randomized three-way crossover study. Aliment Pharmacol Ther 2006;23:1179-1187.

44. Hunt RH, Armstrong D, Yaghoobi M, James C. The pharmacodynamics and pharmacokinetics of S-tenatoprazole-Na $30 \mathrm{mg}, 60 \mathrm{mg}$ and $90 \mathrm{mg}$ vs. esomeprazole $40 \mathrm{mg}$ in healthy male subjects. Aliment Pharmacol Ther 2010;31:648-657.

45. Sachs G, Shin JM, Hunt R. Novel approaches to inhibition of gastric acid secretion. Curr Gastroenterol Rep 2010;12:437-447.

46. Hunt RH, Armstrong D, Yaghoobi M, et al. Predictable prolonged suppression of gastric acidity with a novel proton pump inhibitor, AGN 201904-Z. Aliment Pharmacol Ther 2008;28:187-199.

47. Wang L, Zhou L, Hu H, Lin S, Xia J. Ilaprazole for the treatment of duodenal ulcer: a randomized, double-blind and controlled phase III trial. Curr Med Res Opin 2012;28:101-109.

48. Wang L, Zhou L, Lin S, Hu H, Xia J. A new PPI, ilaprazole compared with omeprazole in the treatment of duodenal ulcer: a randomized double-blind multicenter trial. J Clin Gastroenterol 2011;45:322-329.

49. DU YQ, Guo WY, Zou DW, et al. Acid inhibition effect of ilaprazole on Helicobacter pylori-negative healthy volunteers: an open randomized cross-over study. J Dig Dis 2012;13:113-119.

50. NCT00471094. Safety and Efficacy of Ilaprazole 5, 20 and $40 \mathrm{mg}$ QD and Lansoprazole $30 \mathrm{mg}$ QD on Healing of Erosive Esophagitis (NCT00471094). Available from URL: http://www.clinicaltrials. gov/show/NCT00471094 (accessed November 2013).

51. Hanmi Pharmaceutical Co., Ltd. Hamni press center, latest news. Available from URL: http://www.hanmipharm.com/meng/news/latest_view.asp?seq $=281 \&$ board_id $=7$ (accessed November 2013).

52. U.S Food and Drug Administration (FDA). FDA/Center for Drug Evaluation and Research Office of Communications, Division of Online Communications. Available from URL: http:// www.accessdata.fda.gov/scripts/cder/drugsatfda/index.cfm?fuseaction $=$ Search. Drug Details (accessed November 2013).

53. Chowers Y, Atarot T, Kostadinov A, et al. PPI activity is optimized by VB101, a parietal cell activator. Gastroenterology 2008;134(suppl): A172.

54. Chowers Y, Atarot T, Pratha VS, Fass R. The effect of once daily omeprazole and succinic acid (VECAM) vs once daily omeprazole on 24-h intragastric pH. Neurogastroenterol Motil 2012;24:426431, e208-e209.

55. Orexo announces results confirming the clinical profile of OX17 in reflux disease (GERD). Available from URL: http://www.orexo.com/en/ Investor-Relations/Press-releases/?guid=341021 (accessed November 2013).
56. Dutta U, Armstrong D. Novel pharmaceutical approaches to reflux disease. Gastroenterol Clin North Am 2013;42:93-117.

57. Sorba G, Galli U, Cena C, et al. A new furoxan NO-donor rabeprazole derivative and related compounds. Chembiochem 2003;4:899-903.

58. Andersson K, Carlsson E. Potassium-competitive acid blockade: a new therapeutic strategy in acid-related diseases. Pharmacol Ther 2005;108:294-307.

59. Kahrilas PJ, Dent J, Lauritsen K, et al. A randomized, comparative study of three doses of AZD0865 and esomeprazole for healing of reflux esophagitis. Clin Gastroenterol Hepatol 2007;5:1385-1391.

60. Dent J, Kahrilas PJ, Hatlebakk J, et al. A randomized, comparative trial of a potassium-competitive acid blocker (AZD0865) and esomeprazole for the treatment of patients with nonerosive reflux disease. Am J Gastroenterol 2008;103:20-26.

61. Simon WA, Herrmann M, Klein T, et al. Soraprazan: setting new standards in inhibition of gastric acid secretion. J Pharmacol Exp Ther 2007;321:866-874.

62. Choi HY, Noh YH, Jin SJ, et al. Bioavailability and tolerability of combination treatment with revaprazan $200 \mathrm{mg}+$ itopride $150 \mathrm{mg}$ : a randomized crossover study in healthy male Korean volunteers. Clin Ther 2012;34:1999-2010.

63. Hori Y, Matsukawa J, Takeuchi T, Nishida H, Kajino M, Inatomi N. A study comparing the antisecretory effect of TAK-438, a novel potassium-competitive acid blocker, with lansoprazole in animals. J Pharmacol Exp Ther 2011;337:797-804.

64. Arikawa Y, Nishida H, Kurasawa O, et al. Discovery of a novel pyrrole derivative 1-[5-(2-fluorophenyl)-1-(pyridin-3-ylsulfonyl)$1 \mathrm{H}$-pyrrol-3-yl]-N-methylmethanamine fumarate (TAK-438) as a potassium-competitive acid blocker (P-CAB). J Med Chem 2012;5 5:4446-4456.

65. Hershcovici T, Mashimo H, Fass R. The lower esophageal sphincter. Neurogastroenterol Motil 2011;23:819-830.

66. Rohof WO, Aronica E, Beaumont H, Troost D, Boeckxystaens GE. Localization of mGluR5, GABAB, GABAA, and cannabinoid receptors on the vago-vagal reflex pathway responsible for transient lower esophageal sphincter relaxation in humans: an immunohistochemical study. Neurogastroenterol Motil 2012;24:383, e173.

67. Lehmann A, Blackshaw LA, Brändén L, et al. Cannabinoid receptor agonism inhibits transient lower esophageal sphincter relaxations and reflux in dogs. Gastroenterology 2002;123:1129-1134.

68. Beaumont H, Jensen J, Carlsson A, Ruth M, Lehmann A, Boeckxstaens G. Effect of delta9-tetrahydrocannabinol, a cannabinoid receptor agonist, on the triggering of transient lower oesophageal sphincter relaxations in dogs and humans. Br J Pharmacol 2009;156:153162 .

69. Scarpellini E, Blondeau K, Boecxstaens V, et al. Effect of rimonabant on oesophageal motor function in man. Aliment Pharmacol Ther 2011;33:730-737.

70. Lehmann F, Hildebrand P, Beglinger C. New molecular targets for treatment of peptic ulcer disease. Drugs 2003;63:1785-1797.

71. Clavé P, González A, Moreno A, et al. Endogenous cholecystokinin enhances postprandial gastroesophageal reflux in humans through extrasphincteric receptors. Gastroenterology 1998;115:597-604.

72. Zerbib F, Bruley Des Varannes S, Scarpignato C, et al. Endogenous cholecystokinin in postprandial lower esophageal sphincter function and fundic tone in humans. Am J Physiol 1998;275(6 Pt 1):G1266- 
G1273.

73. Beglinger C, Degen L, Schroller S, D'Amato M, Persiani S. Oral itriglumide, a specific CCK2/gastrin receptor antagonist, inhibits gastrin stimulated gastric acid secretion in humans. Gut 2004; 54(suppl VII):A36.

74. Hershcovici T, Fass R. Transient lower esophageal sphincter relaxation reducers - have we hit a brick wall? Aliment Pharmacol Ther 2011;33:1256-1257.

75. Lal R, Sukbuntherng J, Tai EH, et al. Arbaclofen placarbil, a novel R-baclofen prodrug: improved absorption, distribution, metabolism, and elimination properties compared with R-baclofen. J Pharmacol Exp Ther 2009;330:911-921

76. Vakil NB, Huff FJ, Bian A, Jones DS, Stamler D. Arbaclofen Placarbil in GERD: a randomized, double-blind, placebo-controlled study. Am J Gastroenterol 2011;106:1427-1438.

77. Boeckxstaens GE, Beaumont H, Mertens V, et al. Effects of lesogaberan on reflux and lower esophageal sphincter function in patients with gastroesophageal reflux disease. Gastroenterology 2010;139:409-417.

78. Boeckxstaens GE, Beaumont H, Hatlebakk J, Silberg D, Adler J, Denison H. Efficacy and tolerability of the novel reflux inhibitor, AZD3355, as add-on treatment in GERD patients with symptoms despite proton pump inhibitor therapy. Gastroenterology 2009;136(suppl 1):A436.

79. Zerbib F, Bruley des Varannes S, Roman S, et al. Randomised clinical trial: effects of monotherapy with ADX10059, a mGluR5 inhibitor, on symptoms and reflux events in patients with gastrooesophageal reflux disease. Aliment Pharmacol Ther 2011;33:911921.

80. Rohof WO, Lei A, Hirsch DP, et al. The effects of a novel metabotropic glutamate receptor 5 antagonist (AZD2066) on transient lower oesophageal sphincter relaxations and reflux episodes in healthy volunteers. Aliment Pharmacol Ther 2012;35:1231-1242.

81. Ruth M, Hamelin B, Röhss K, Lundell L. The effect of mosapride, a novel prokinetic, on acid reflux variables in patients with gastro-oesophageal reflux disease. Aliment Pharmacol Ther 1998; 12:35-40.

82. Futagami S, Iwakiri K, Shindo T, et al. The prokinetic effect of mosapride citrate combined with omeprazole therapy improves clinical symptoms and gastric emptying in PPI-resistant NERD patients with delayed gastric emptying. J Gastroenterol 2010;45:413-421.

83. Kim YS, Kim TH, Choi CS, et al. Effect of itopride, a new proki- netic, in patients with mild GERD: a pilot study. World J Gastroenterol 2005;11:4210-4214.

84. Rohof WO, Bennink RJ, de Ruigh AA, Hirsch DP, Zwinderman AH, Boeckxstaens GE. Effect of azithromycin on acid reflux, hiatus hernia and proximal acid pocket in the postprandial period. Gut 2012;61:1670-1677.

85. Mertens V, Blondeau K, Pauwels A, et al. Azithromycin reduces gastroesophageal reflux and aspiration in lung transplant recipients. Dig Dis Sci 2009;54:972-979.

86. Frampton JE. Prucalopride. Drugs 2009;69:2463-2476.

87. Choung RS, Ferguson DD, Murray JA, et al. A novel partial $5 \mathrm{HT}_{3}$ agonist DDP733 after a standard refluxogenic meal reduces reflux events: a randomized, double-blind, placebo-controlled pharmacodynamic study. Aliment Pharmacol Ther 2008;27:404-411.

88. Krarup AL, Ny L, Astrand M, et al. Randomised clinical trial: the efficacy of a transient receptor potential vanilloid 1 antagonist AZD1386 in human oesophageal pain. Aliment Pharmacol Ther 2011;22:1113-1122.

89. Fass R. Functional heartburn: what it is and how to treat it. Gastrointest Endosc Clin N Am 2009;19:23-33.

90. Hershcovici T, Achem SR, Jha LK, Fass R. Systematic review: the treatment of noncardiac chest pain. Aliment Pharmacol Ther 2012;35:5-14.

91. Fass R, Dickman R. Non-cardiac chest pain: an update. Neurogastroenterol Motil 2006;18:408-417.

92. Kort ME, Kym PR. TRPV1 antagonists: clinical setbacks and prospects for future development. Prog Med Chem 2012;51:57-70.

93. Gunthorpe MJ, Chizh BA. Clinical development of TRPV1 antagonists: targeting a pivotal point in the pain pathway. Drug Discov Today 2009;14:56-67.

94. Adachi K, Furuta K, Miwa H, et al. A study on the efficacy of rebamipide for patients with proton pump inhibitor-refractory noneroxive reflux disease. Dig Dis Sci 2012;57:1609-1617.

95. Araki $\mathrm{H}$, Kato $\mathrm{T}$, Onogi $\mathrm{F}$, et al. Combination of proton pump inhibitor and rebamipide, a free radical scavenger, promotes artificial ulcer healing after endoscopic submucosal dissection with dissection size > 40 mm. J Clin Biochem Nutr 2012;51:185-188.

96. Kawahara Y, Nakase Y, Isomoto Y, et al. Role of macrophage colony-stimulating factor (M-CSF)-dependent macrophages in gastric ulcer healing in mice. J Physiol Pharmacol 2011;62:441-448. 